\title{
Major Surgical Treatment of Osteoporotic Vertebral Fractures in the Elderly: A Comparison of Anterior Spinal Fusion, Anterior-Posterior Combined Surgery and Posterior Closing Wedge Osteotomy
}

\author{
Shota Takenaka, Yoshihiro Mukai, Noboru Hosono, Takeshi Fuji \\ Department of Orthopaedic Surgery, Japan Community Health care Organization Osaka Hospital, Osaka, Japan
}

\begin{abstract}
Study Design: A retrospective study.
Purpose: To clarify the differences among the three major surgeries for osteoporotic vertebral fractures based on the clinical and radiological results.

Overview of Literature: Minimally invasive surgery like balloon kyphoplasty has been used to treat osteoporotic vertebral fractures, but major surgery is necessary for severely impaired patients. However, there are controversies on the surgical procedures.

Methods: The clinical and radiographic results of patients who underwent major surgery for osteoporotic vertebral fracture were retrospectively compared, among anterior spinal fusion (group A, 9 patients), single-stage combined anterior-posterior procedure (group AP, 8 patients) and posterior closing wedge osteotomy (group P, 9 patients). Patients who underwent revision surgery were evaluated just before the revision surgery, and the other patients were evaluated at the final follow-up examination, which was defined as the end point of the evaluations for the comparison.

Results: The operation time was significantly longer in group AP than in the other two groups. The postoperative correction of kyphosis was significantly greater in group $P$ than in group $A$. Although the differences were not significant, better outcomes were obtained in group $P$ in: back pain relief at the end point; ambulatory ability at the end point; and average loss of correction.

Conclusions: The posterior closing wedge osteotomy demonstrated better surgical results than the anterior spinal fusion procedure and the single-stage combined anterior-posterior procedure.
\end{abstract}

Keywords: Osteoporosis; Vertebral body fracture; Posterior closing wedge osteotomy; Single-stage combined anterior-posterior procedure; Anterior spinal fusion

\section{Introduction}

The number of patients with vertebral fractures associated with osteoporosis has increased dramatically [1]. Most of the patients can be treated conservatively, but $13.5 \%$ develop pseudarthrosis [2]. Moreover, 3\% develops late- onset paresis [3]. Recently, minimally invasive surgeries, such as balloon kyphoplasty and vertebroplasty, have been used to treat osteoporotic vertebral fractures $[4,5]$. However, major surgery is still needed for severely impaired patients who lose walking ability with neurologic compromise. However, there are controversies on the

Received May 10, 2013; Revised Jul 30, 2013; Accepted Aug 8, 2013

Corresponding author: Shota Takenaka

Department of Orthopaedic Surgery, Japan Community Health care Organization Osaka Hospital,

4-2-78 Fukushima, Osaka 553-0003, Japan

Tel: +81-6-6441-5451, Fax: +81-6-6445-8900,E-mail: show@yb3.so-net.ne.jp 
surgical procedures, which include anterior spinal fixation [6-9], combined anterior-posterior procedure and posterior closing wedge osteotomy [10].

In previous reports, two surgical procedures for osteoporotic fractures were compared based on the final follow-up status $[11,12]$. However, revision surgery is extremely demanding, both for elderly patients and surgeons, and may cause complications [13]. In the present study, the patients who underwent revision surgery were evaluated just before the revision surgery, and the others were evaluated at the final follow-up, defined as the end point of evaluation in the comparison.

The aim of this study was to elucidate the differences among the three major surgeries for osteoporotic vertebral fractures, using clinical and radiological investigations.

\section{Materials and Methods}

Study subjects were 41 consecutive patients who underwent a major surgery for osteoporotic vertebral fracture from January 1998 to December 2009 in our hospital. Excluded were 2 patients with a previous surgery at the same spinal level, 4 patients with less than 180 days follow-up and 9 patients who underwent other surgical procedures including posterior lumbar interbody fusion. Finally 26 patients ( 9 men and 17 women) were enrolled in this retrospective study. The patients were stratified into three groups by surgical procedure. Nine patients underwent an anterior spinal fusion, 8 patients underwent a single-stage anterior and posterior combined procedure (group AP) and 9 patients underwent a posterior closing wedge osteotomy (group P).

The average age at surgery was 72.2 years (range, 60-81 years). The mean follow-up period was 38.5 months (range, 6.1-109 months). The indication for the operation was persistent neurological deficit. No patient had undergone a previous spinal surgery at the same site.

The etiologies were falls in 13 patients, lifting a heavy load in 3, bowling in 1, and unknown in 9. The affected vertebrae were T10 in 1 patient, T11 in 3, T12 in 8, L1 in 8, L1 and L2 (2-level vertebral fracture) in 2, L2 in 3, L3 in 2, and L4 in 1. Nineteen patients (73\%) suffered a transient lesion (T11-L1). All patients had osteoporosis greater than Saville grade II [14]. The mean duration between onset and surgery was 12.1 months (range, 1.2-68.8 months). Revision surgery was defined as any procedure that was required due to severe pain or neurological dete- rioration during the follow-up period.

Patients who underwent revision surgery were evaluated just before the revision surgery, and the other patients were evaluated at the final follow-up examination, which was defined as the end point of the evaluation for the comparison.

Patient characteristics, including sex, age at surgery, body mass index (BMI), operating time, blood loss and clinical outcome, which consisted of back pain, urinary dysfunction, and ambulatory ability, were compared. The radiographic findings, including compressed morphology, kyphosis angle, pre-existing vertebral fractures and postoperative vertebral fractures, were also examined. The protocol was approved by the institutional review boards of the hospital.

\section{Clinical evaluation}

The severity of the back pain (back pain score) was evaluated as follows: 0 , intolerable severe pain despite using analgesics; 1 , able to control pain using analgesics; 2 , within tolerable levels without analgesics; and 3, almost none. Eight patients were rated as grade 0,14 were grade 1 , and 4 were grade 2 before surgery. Urinary dysfunction was classified into four grades (urinary dysfunction score): 0 , urinary retention or urinary incontinence; 1 , residual urine; 2 , frequent urination or difficulty in starting urination; and 3, normal. Urinary dysfunction before surgery was grade 0 in 3 patients, grade 1 in 2, grade 2 in 4 , and grade 3 in 17. Ambulatory ability including neurological function was assessed by a modified Frankel grading system without evaluation of urinary dysfunction (Table 1) $[15,16]$. The preoperative modified Frankel grade was $\mathrm{C} 1$ in 2 patients, $\mathrm{C} 2$ in $8, \mathrm{D} 1$ in 8 , and $\mathrm{D} 2$ in 8.

\section{Radiologic evaluation}

The radiologic data for 20 out of 26 patients were available. Morphology of the fractured vertebra was classified into two groups: burst fracture type with middle column collapsed and compression fracture type with middle column intact. The kyphosis angle was determined by the Cobb angle method on lateral radiographs, as the angle between the upper endplate of the uninvolved vertebra above the fractured level and the lower endplate of the uninvolved vertebra below the fractured level. The kyphosis angle was assessed before surgery, immediately after surgery and 
Table 1. Modified Frankel grade

\begin{tabular}{ll}
\hline A & Complete motor and sensory loss \\
B & Preserved sensation only, voluntary motor function absent \\
C & Preserved motor less than fair grade (nonfunctional for any useful purpose) \\
& C1 Manual muscle testing grade approximately 1 or 2 in the lower limbs \\
C2 Manual muscle testing grade approximately 3 in the lower limbs, able to flex knee in the supine position \\
Motor useful \\
D1 Able to walk less than 100 m indoors \\
D2 Able to walk with a cane, walker or crutches even out of doors \\
D3 Independent ambulation without support
\end{tabular}

Urinary dysfunction is not included. If the assessment is uncertain, it is categorized into the lower grade.

at the end point. The correction angle was defined as the difference between the preoperative and the immediately postoperative kyphosis angles. The correction loss was calculated by the difference between the kyphosis angle immediately after surgery and that at the end point.

\section{Surgical procedures}

In group $\mathrm{A}$, for anterior column support, cylindrical titanium cages were used in 7 patients, and autologous iliac bone grafts were used in 2. Additionally, anterior verte- bral plates were placed in 7 patients. In group AP, for anterior column support, autologous iliac bone grafts were harvested in 5 patients, and cylindrical titanium cages were used in 3 patients. For posterior instrumentation, pedicle screws were inserted from two levels above to two levels below the affected vertebra in 5 patients, spinous process plates were used in 2 , and a hook-claw system was used in 1. In group P, pedicle screws were inserted from two levels above to two or three levels below the affected vertebra in 7 patients (Fig. 1), and spinous process plates were used in 2. Decompression and a vertebral shorten-
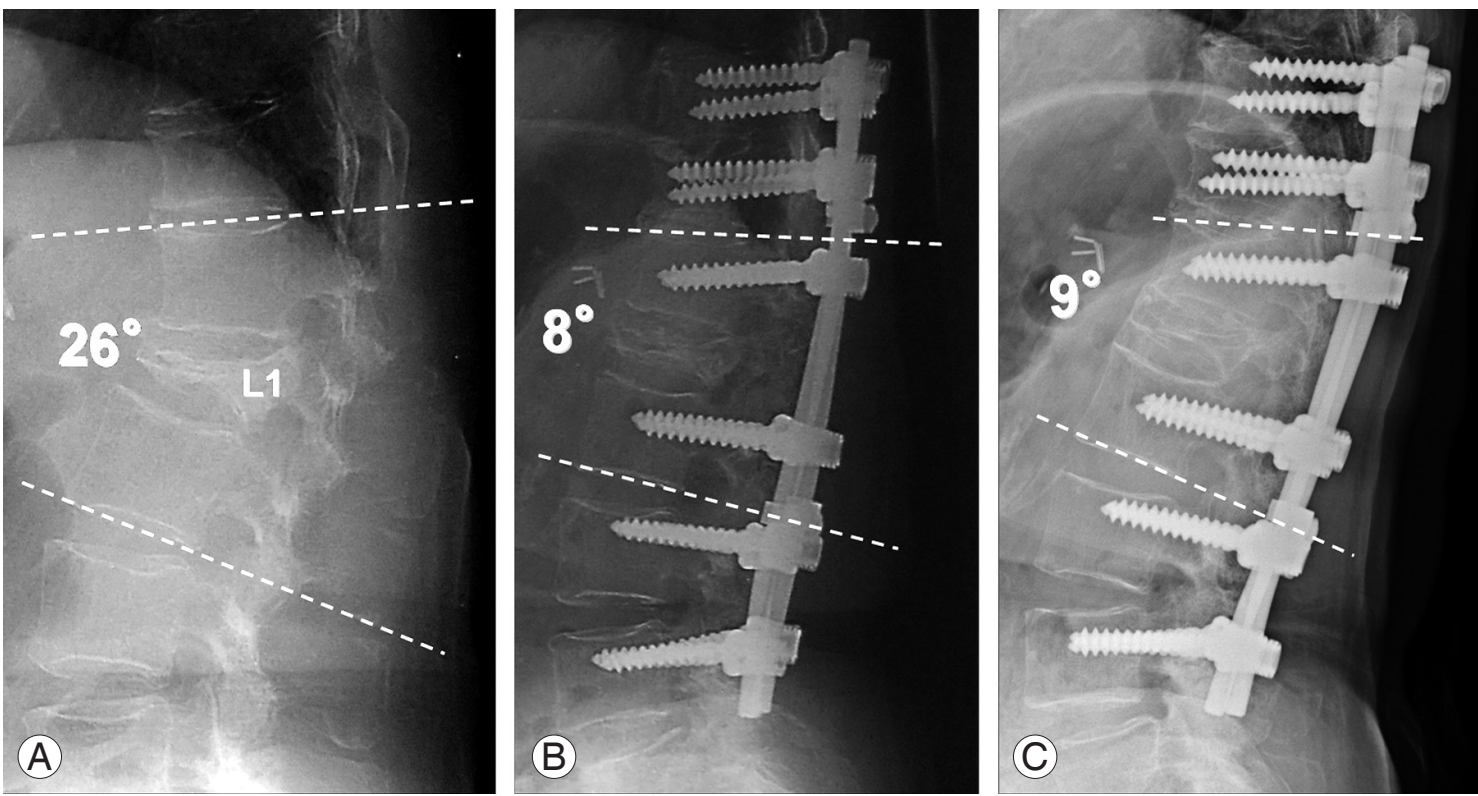

Fig. 1. A 78-year-old woman had back pain after falling down, having developed an L1 vertebral fracture of burst fracture type (A). A neurological deficit developed 3 weeks after onset. When she was admitted to our hospital, she was unable to walk independently. The preoperative back pain score was grade 1, the urinary dysfunction score was grade 3, and the modified Frankel grade was C1. She underwent posterior subtraction osteotomy for the L1 vertebra with posterior instrumentation from T10 to L4 (B). Pedicle screws and sublaminar wiring were used in the instrumentation. The local kyphosis was corrected from $26^{\circ}$ before surgery to $8^{\circ}$ right after surgery. The kyphosis remained almost unchanged at $9^{\circ}$, and bone union was obtained at the end point (C). The back pain was relieved to grade 3 at the end point. Similarly, the modified Frankel grade recovered to D2. 
Table 2. Patient demographics

\begin{tabular}{|c|c|c|c|c|}
\hline & Group A & Group AP & Group P & $p$-value \\
\hline No. of patients & 9 & 8 & 9 & - \\
\hline Male:female & $5: 4$ & $1: 7$ & $3: 6$ & $0.264^{\mathrm{a})}$ \\
\hline Age at surgery (yr) & $72.1 \pm 4.5(67-81)$ & $70.6 \pm 6.9(60-80)$ & $73.8 \pm 3.4(68-78)$ & $0.463^{b)}$ \\
\hline Body mass index $\left(\mathrm{kg} / \mathrm{m}^{2}\right)$ & $22.1 \pm 3.0(16.0-25.3)$ & $23.8 \pm 3.2(19.1-30.3)$ & $24.4 \pm 2.9(21.0-28.6)$ & $0.383^{\mathrm{bl}}$ \\
\hline $\begin{array}{l}\text { Duration between the onset and } \\
\text { surgery (mo) }\end{array}$ & $14.2 \pm 21.0(1.4-68.8)$ & $12.3 \pm 11.2(2.0-36.9)$ & $10.1 \pm 9.3(1.2-29.3)$ & $0.799^{\mathrm{bl}}$ \\
\hline Follow-up period (mo) & $33.0 \pm 27.0(6.1-68.9)$ & $46.8 \pm 34.4(10.3-109.8)$ & $41.6 \pm 16.7(23.8-72.8)$ & $0.795^{\mathrm{bl}}$ \\
\hline
\end{tabular}

Values are presented as mean \pm standard deviation (range). There are no significant differences among the three groups.

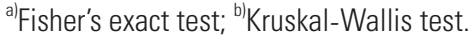

ing procedure were performed according to the previous reports $[10,11]$. The average years of experience were 20.4 years (7.3-32.6 years) for the surgeons in this study. For the three surgeries performed by surgeons with less than 10 years of experience, senior surgeons with over 20 years of experience assisted.

\section{Statistical analysis}

PASW ver. 18 (SPSS Inc., Chicago, IL, USA) was used for the analysis. $p<0.05$ were considered significant when comparing two groups, using the Mann-Whitney U test and Fisher's exact test. To compare three groups, the Kruskal-Wallis test was used. When there was a significant difference, the Mann-Whitney U test was used to compare two groups with a significant difference, defined as a $p$-value $<0.017$, using the Bonferroni adjustment.

\section{Results}

Group A, group AP, and group P were comparable with respect to the sex ratio, age at surgery, $\mathrm{BMI}$, time between onset and surgery and the follow-up period (Table 2). There were no significant differences among the three groups in preoperative back pain, urinary dysfunction, modified Frankel grade (Table 3), kyphosis angle and preexisting vertebral fractures (Table 4). The selection of the surgical procedure was not controlled in this study, but there was no disparity in the preoperative status of the three groups.

Preoperative back pain and urinary dysfunction were significantly improved at the end point in group A $(p=0.021)$, group AP $(p=0.038)$, and group $\mathrm{P}(p=0.007)$. There were significant improvements in the modi- fied Frankel grade, in group AP $(p=0.041)$ and group P $(p=0.034)$, from before surgery to the end point. There was no significant difference in group A in the modified Frankel grade, between before surgery and at the end point $(p=0.206)$.

The operation time was significantly longer in group AP than in the other two groups (group AP vs. group A, $p=0.006$ and group AP vs. group $\mathrm{P}, p=0.004$ ), whereas the three groups were comparable in blood loss (Table 3 ).

Although the differences were not significant, the back pain score was higher in group $\mathrm{P}$ than in group $\mathrm{A}$ and group AP at the end point $(p=0.05, p=0.07)$. There were no significant differences in urinary dysfunction among the three groups at the end point. The modified Frankel grade was better in group $\mathrm{P}$ than in group $\mathrm{A}$ at the end point, but the difference was not significant $(p=0.04)$. The difference between group AP and group P was not significant $(p=0.28)$ (Table 4$)$.

The correction angle immediately after surgery was significantly greater in group P than in group A $(p=0.005)$. The correction loss was greater in group AP than in group P, but the difference was not significant $(p=0.02)$. The difference between group A and group $\mathrm{P}$ was also not significant $(p=0.78)$.

Overall, 4 of 6 patients in group A, 1 of 5 in group AP, and 4 of 9 in group $P$ had subsequent postoperative vertebral fractures. All subsequent vertebral fractures were controlled conservatively. The earliest of them occurred one month after surgery. Six of the nine subsequent fractures contained the cranial end of the instrumentation.

\section{Revision surgery}

Revision surgery was performed in 3 of 9 group A pa- 
Table 3. Clinical evaluation

\begin{tabular}{|c|c|c|c|c|c|c|}
\hline & Grade & Group A & Group AP & Group P & $\begin{array}{c}\text { Three-group } \\
\text { comparison } \\
p \text {-value }{ }^{\mathrm{a})}\end{array}$ & $\begin{array}{c}\text { Two-group } \\
\text { comparison } \\
p \text {-value }{ }^{b}\end{array}$ \\
\hline Back pain score before surgery & $\begin{array}{l}0 \\
1 \\
2 \\
3\end{array}$ & $\begin{array}{l}2 \\
6 \\
1 \\
0\end{array}$ & $\begin{array}{l}3 \\
4 \\
1 \\
0\end{array}$ & $\begin{array}{l}3 \\
4 \\
2 \\
0\end{array}$ & 0.883 & \\
\hline Back pain score at the end point & $\begin{array}{l}0 \\
1 \\
2 \\
3\end{array}$ & $\begin{array}{l}1 \\
1 \\
6 \\
1\end{array}$ & $\begin{array}{l}1 \\
3 \\
2 \\
2\end{array}$ & $\begin{array}{l}0 \\
0 \\
4 \\
5\end{array}$ & 0.058 & A-P: 0.050 \\
\hline Urinary dysfunction score before surgery & $\begin{array}{l}0 \\
1 \\
2 \\
3\end{array}$ & $\begin{array}{l}1 \\
0 \\
0 \\
8\end{array}$ & $\begin{array}{l}1 \\
1 \\
2 \\
4\end{array}$ & $\begin{array}{l}1 \\
1 \\
2 \\
5\end{array}$ & 0.289 & \\
\hline Urinary dysfunction score at the end point & $\begin{array}{l}0 \\
1 \\
2 \\
3\end{array}$ & $\begin{array}{l}1 \\
0 \\
0 \\
8\end{array}$ & $\begin{array}{l}1 \\
0 \\
1 \\
6\end{array}$ & $\begin{array}{l}0 \\
1 \\
2 \\
6\end{array}$ & 0.656 & \\
\hline Modified Frankel grade before surgery & $\begin{array}{l}\text { B } \\
\text { C1 } \\
\text { C2 } \\
\text { D1 } \\
\text { D2 } \\
\text { D3 }\end{array}$ & $\begin{array}{l}0 \\
0 \\
5 \\
3 \\
1 \\
0\end{array}$ & $\begin{array}{l}0 \\
1 \\
2 \\
2 \\
3 \\
0\end{array}$ & $\begin{array}{l}0 \\
1 \\
1 \\
3 \\
4 \\
0\end{array}$ & 0.377 & \\
\hline Modified Frankel grade at the end point & $\begin{array}{l}\text { B } \\
\text { C1 } \\
\text { C2 } \\
\text { D1 } \\
\text { D2 } \\
\text { D3 } \\
\text { E }\end{array}$ & $\begin{array}{l}0 \\
0 \\
2 \\
5 \\
1 \\
1 \\
0\end{array}$ & $\begin{array}{l}0 \\
0 \\
1 \\
3 \\
3 \\
0 \\
1\end{array}$ & $\begin{array}{l}0 \\
0 \\
1 \\
0 \\
6 \\
1 \\
1\end{array}$ & 0.089 & A-P: 0.040 \\
\hline
\end{tabular}

Although the differences are not significant, group P shows better outcomes with respect to back pain relief and ambulatory ability at the end point than group $A$.

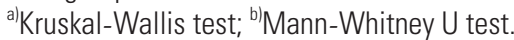

tients, 4 of 8 group AP patients (including only a removal of instrumentation in 2) and in 1 of 9 group P patients. After excluding removal of instrumentation only in 2 patients, in the other 6 revision surgeries, the average operating time was 292 minutes, and the average blood loss was $1,375 \mathrm{~mL}$, which were extremely demanding for the elderly patients. The revision procedures are shown in Table 5. In two patients in group A, a removal of the anterior cages was needed during the revision surgeries (Fig. 2). Two patients in group AP required a removal of the posterior instrumentation due to skin protrusion. The remaining two patients in group AP required extension of the posterior instrumentation owing to sinking of the anterior cage. One patient in group P required a revision surgery due to the failure of a spinous plate.

Four patients developed early postoperative complications. Postoperative pneumonia developed in 1 patient, postoperative pleural effusion occurred in 1, and superficial infection at the iliac crest was seen in 1 patient in group A. In group AP, a patient developed acute intensive care unit psychosis. There were no postoperative early complications in group P. There were no deep wound infections in this study group.

\section{Discussion}

When performing a surgery for osteoporotic vertebral fractures, three aspects must be considered: patient fac- 
Table 4. Radiologic characteristics, operation time, and blood loss

\begin{tabular}{|c|c|c|c|c|c|}
\hline Characteristic & Group A & Group AP & Group P & $\begin{array}{l}\text { Three-group } \\
\text { comparison } \\
p \text {-value }\end{array}$ & $\begin{array}{l}\text { Two-group } \\
\text { comparison } \\
p \text {-value }\end{array}$ \\
\hline Operation time (min) & $\begin{array}{c}256 \pm 68 \\
(131-365)\end{array}$ & $\begin{array}{c}347 \pm 66 \\
(280-466)\end{array}$ & $\begin{array}{c}248 \pm 62 \\
(173-365)\end{array}$ & $0.007^{a)}$ & $\begin{array}{l}\text { A-AP: } 0.006^{b /} \\
\text { P-AP: } 0.004^{\text {b) }}\end{array}$ \\
\hline Blood loss (mL) & $\begin{array}{c}1,644 \pm 1,159 \\
(50-3700)\end{array}$ & $\begin{array}{c}1,800 \pm 1,383 \\
(400-4300)\end{array}$ & $\begin{array}{c}956 \pm 505 \\
(400-1,800)\end{array}$ & $0.233^{\text {a) }}$ & \\
\hline $\begin{array}{l}\text { Preoperative affected vertebra } \\
\text { morphology (burst fracture: } \\
\text { compression type) }\end{array}$ & $6: 0$ & $3: 2$ & $8: 1$ & $0.297^{c l}$ & \\
\hline Pre-existing vertebral fracture & 2 & 3 & 4 & $0.689^{a)}$ & \\
\hline Postoperative vertebral fracture & 4 & 1 & 4 & $0.320^{\mathrm{a})}$ & \\
\hline \multicolumn{6}{|l|}{ Kyphosis } \\
\hline Preoperative & $\begin{array}{l}22.0 \pm 19.2 \\
(1.0-46.0)\end{array}$ & $\begin{array}{c}27.7 \pm 14.8 \\
(11.5-48.0)\end{array}$ & $\begin{array}{l}33.7 \pm 17.2 \\
(5.0-60.9)\end{array}$ & $0.424^{\text {a) }}$ & \\
\hline Immediate postoperative & $\begin{array}{r}18.3 \pm 15.9 \\
(1.0-40.0)\end{array}$ & $\begin{array}{c}12.7 \pm 16.9 \\
(-12.6-29.0)\end{array}$ & $\begin{array}{c}14.9 \pm 9.4 \\
(-1.0-24.0)\end{array}$ & $0.970^{\text {a) }}$ & \\
\hline At the end point & $\begin{array}{c}29.5 \pm 21.9 \\
(12.0-60.0)\end{array}$ & $\begin{array}{l}31.5 \pm 18.0 \\
(6.7-53.0)\end{array}$ & $\begin{array}{l}26.0 \pm 11.2 \\
(8.7-41.8)\end{array}$ & $0.926^{\text {a) }}$ & \\
\hline Correction & $\begin{array}{c}3.7 \pm 3.9 \\
(0-11.0)\end{array}$ & $\begin{array}{l}15.0 \pm 11.0 \\
(1.0-28.0)\end{array}$ & $\begin{array}{l}18.9 \pm 11.2 \\
(2.0-41.2)\end{array}$ & $0.027^{\text {a) }}$ & A-P: $0.005^{b)}$ \\
\hline Correction loss & $\begin{array}{l}11.2 \pm 8.6 \\
(0-25.0)\end{array}$ & $\begin{array}{c}18.9 \pm 3.7 \\
(14.0-24.0)\end{array}$ & $\begin{array}{l}11.1 \pm 12.6 \\
(1.0-43.0)\end{array}$ & $0.063^{\mathrm{a})}$ & P-AP: $0.020^{b)}$ \\
\hline
\end{tabular}

Values are presented as mean \pm standard deviation (range).

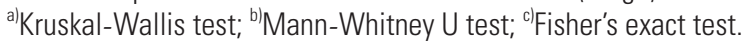

Table 5. Revision surgery

\begin{tabular}{llrr} 
Group & Operative procedure & Operation time (min) & Blood loss (mL) \\
\hline A-1 & PLF with PS & 112 & 650 \\
A-2 & $\begin{array}{l}\text { Removing anterior cage, adding posterior } \\
\text { fixation with PS }\end{array}$ & 294 & 700 \\
\hline A-3 & $\begin{array}{l}\text { Removing anterior cage, adding posterior } \\
\text { fixation with PS }\end{array}$ & 76 & 1,200 \\
AP-1 & Removing instrumentation & 50 & 80 \\
\hline AP-2 & Removing instrumentation & 250 & 2,600 \\
AP-3 & Elongating posterior fixation with PS & 300 & 1,600 \\
\hline AP-4 & Adding posterior fixation with PS & 315 & 1,500 \\
P-1 & Adding posterior fixation with PS & 235 & 964 \\
\hline Average & & 284 & 1,221 \\
\hline Average without AP-1 and AP-2 & & & 500 \\
\hline
\end{tabular}

PLF, posterolateral fusion; PS, pedicle screws.

tors, surgeon factors and surgical procedures. Patient factors include 1) localization of compression if anterior and/or a posterior site is involved; 2) severity of osteoporosis, especially pre-existing multiple vertebral fractures; and 3) general medical condition of the patients, including pulmonary or cardiovascular diseases. The surgeon factor is the surgeon's experience. Various surgical procedures have recently been advocated for osteoporotic 
vertebral fractures, such as anterior spinal fusion, anterior-posterior combined surgery, posterior subtraction osteotomy, posterior approach decompression and fusion [17], posterior fusion with cementing [18] and posterior fusion without instrumentation [19]. No prospective studies have been reported, not only because of the rarity of indications for open surgical intervention for this population, but also because of the difficulty in compar-
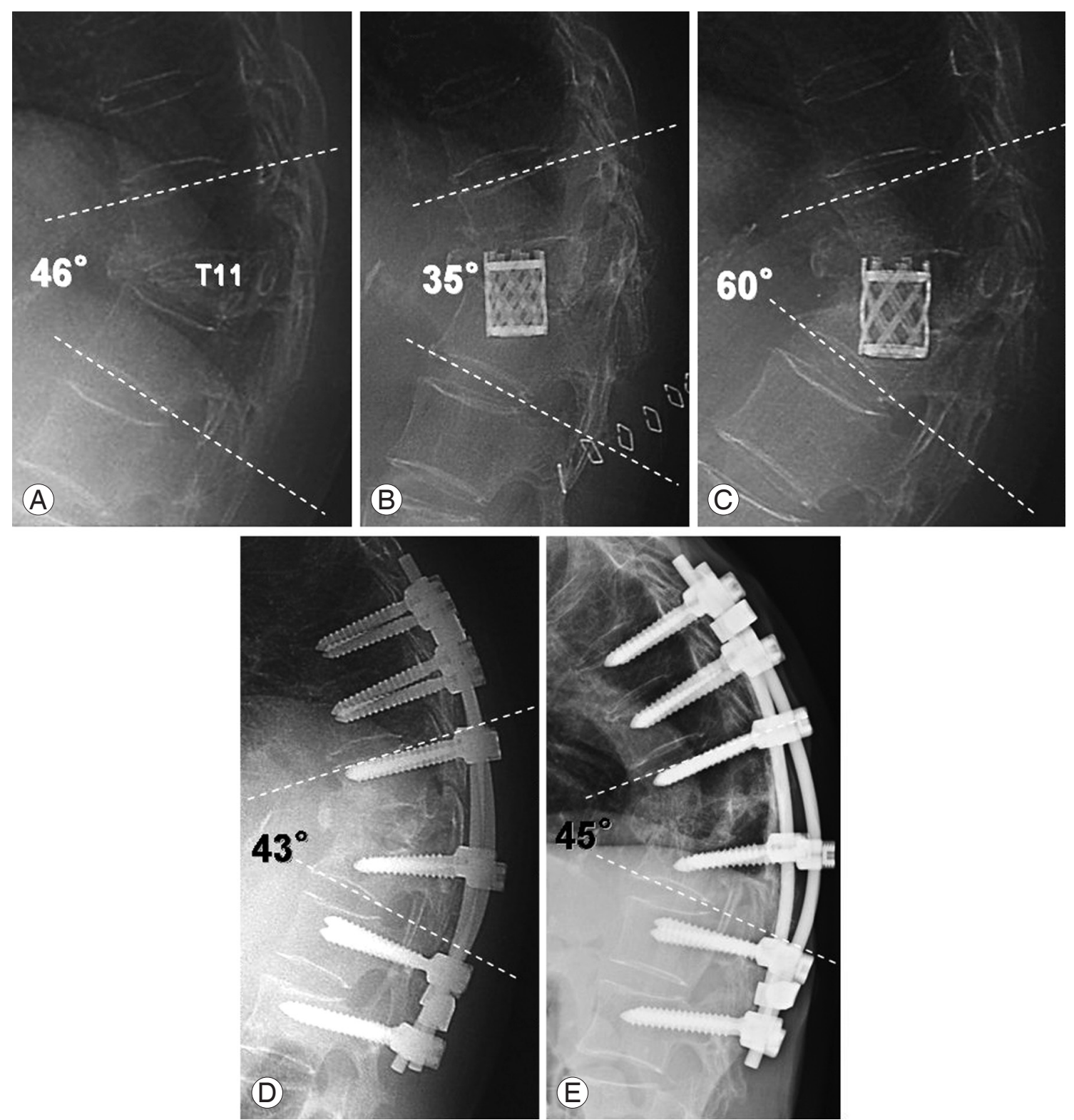

Fig. 2. A 72-year-old woman with Parkinson's disease developed back pain. The cause of her T11 vertebral fracture was unclear (A). The morphology of the fracture was burst fracture type. She was admitted to our hospital 5 years after the back pain started. Her chief complaint was severe back pain and difficulty in walking independently. The preoperative back pain score was grade 1 , the urinary dysfunction score was grade 3, and the modified Frankel grade was D2. Anterior fusion was performed using a titanium cage as an anterior strut. Four days after surgery, the cage subsided into the caudal vertebral body (B). The cage subsidence showed a gradual increase over time (C). One year after the initial surgery, she developed an L2 vertebral fracture. At that point, her back pain score and modified Frankel grade decreased to grade 0 and D1, respectively. The anterior strut was removed, and posterior instrumentation with subtraction osteotomy and sublaminar wiring was added from three levels above to three levels below the affected vertebra in the revision surgery to salvage the situation (D). The preoperative kyphosis of $46^{\circ}$ decreased to $35^{\circ}$ immediately after surgery, but it increased to $60^{\circ}$ immediately before the salvage operation. Two years after the salvage operation, the kyphosis was $45^{\circ}$, the back pain score was grade 2, the urinary dysfunction score was grade 3 , and the modified Frankel grade was D2 (E). 
ing several procedures with similar patient conditions and an identical operator. In the previous reports, some surgical procedures were compared at the final follow up. As mentioned above, revision surgeries carry very high risks. The comparison at the final follow-up is thought to be inadequate for the comparison between some procedures. In this study, the comparison was performed at the end point. The patients who underwent revision surgery were evaluated just before the revision surgery, and the others were seen at the final follow-up, which was defined as the end point of evaluation for the comparison.

Several authors proposed that anterior spinal fusion is safe because of the direct visualization of the decompression site and the preservation of the posterior support tissues $[2,6-8]$. They have also stated that the procedure can resolve both the anterior instability and the compression in one stage. However, poor bone quality in the adjacent vertebrae, as well as the collapsed vertebra, may cause subsidence of anterior grafts. Consequently, relapse of kyphosis can lead to revision surgery. Kanayama et al. [9] reported that only $15 \%$ of single-level anterior fusions underwent revision surgery, but $40 \%$ of two-level surgeries necessitated additional posterior fusion. Taneichi et al. [3] also pointed out that in $50 \%$ of anterior surgeries, a revision surgery is needed. In this study, 3 of 9 patients in group A showed postoperative progression of kyphosis and required revision surgery. The patients in group A experienced neurological improvements right after the operation. However group A included three revision operations in which the patients' neurological status was deteriorated right before the revision surgery. The neurological deterioration led to non-significant changes in group A regarding the results of modified Frankel grade at the end point. Moreover, in order to prevent the subsidence, it is important for surgeons to choose an appropriate anterior strut in terms of the size and the insert direction.

Suk et al. [11] reported that posterior subtraction osteotomy is technically demanding, but less invasive than anterior and posterior combined surgery. The two surgical procedures were comparable in their clinical results. They concluded that posterior subtraction osteotomy was a favorable option. In this study, the operation time was significantly longer in group AP than in the other two groups. The postoperative correction of kyphosis was significantly greater in group $\mathrm{P}$ than in group A. Although the differences were not significant, better outcomes were obtained in group $P$ in 1) back pain relief at the end point; 2) ambulatory ability at the end point; 3 ) average loss of correction; and 4) a lower incidence of revision surgery. Group P had better surgical results at the end point.

However, posterior subtraction osteotomy also has some potential risks. As in the revision surgery for the procedure in this study, a beak-like appearance can lead to instrumentation failure. Moreover, spinal shortening could increase the protrusion of the posterior column of the affected vertebral body. Intraoperative ultrasound imaging is useful and recommended to detect the protrusion [20]. Other authors reported that there was a significant difference between the correction angle and postoperative instrument failure. They proposed that overcorrection should be avoided to prevent postoperative instrument failure. The mean correction angle in the group with instrument failure after surgery was $26.4^{\circ}$, whereas that in the group without instrument failure was $17.5^{\circ}[21]$.

\section{Conclusions}

Operation time was significantly longer in group AP than in the other two groups. The postoperative correction of kyphosis was significantly greater in group $\mathrm{P}$ than in group A. Although the differences were not significant, group P showed better outcomes with respect to back pain relief at the end point, ambulatory ability at the end point and average loss of correction.

\section{References}

1. Bow $\mathrm{CH}$, Cheung E, Cheung CL, et al. Ethnic difference of clinical vertebral fracture risk. Osteoporos Int 2012;23:879-85.

2. Tsujio T, Nakamura $\mathrm{H}$, Terai $\mathrm{H}$, et al. Characteristic radiographic or magnetic resonance images of fresh osteoporotic vertebral fractures predicting potential risk for nonunion: a prospective multicenter study. Spine (Phila Pa 1976) 2011;36:1229-35.

3. Taneichi H, Kaneda K, Oguma T, Okaji M. Risk factor analysis for osteoporotic vertebral collapse and pseudarthrosis. Rinsho Seikei Geka 2002;37:437-42

4. Garfin SR, Yuan HA, Reiley MA. New technologies in spine: kyphoplasty and vertebroplasty for the treatment of painful osteoporotic compression fractures. 
Spine (Phila Pa 1976) 2001;26:1511-5.

5. Galibert P, Deramond H, Rosat P, Le Gars D. Preliminary note on the treatment of vertebral angioma by percutaneous acrylic vertebroplasty. Neurochirurgie 1987;33:166-8.

6. McAfee PC, Bohlman HH, Yuan HA. Anterior decompression of traumatic thoracolumbar fractures with incomplete neurological deficit using a retroperitoneal approach. J Bone Joint Surg Am 1985;67:89104.

7. Kaneda K, Asano S, Hashimoto T, Satoh S, Fujiya M. The treatment of osteoporotic-posttraumatic vertebral collapse using the Kaneda device and a bioactive ceramic vertebral prosthesis. Spine (Phila Pa 1976) 1992;17(8 Suppl):S295-303.

8. Uchida K, Kobayashi S, Nakajima H, et al. Anterior expandable strut cage replacement for osteoporotic thoracolumbar vertebral collapse. J Neurosurg Spine 2006;4:454-62.

9. Kanayama M, Ishida T, Hashimoto T, et al. Role of major spine surgery using Kaneda anterior instrumentation for osteoporotic vertebral collapse. J Spinal Disord Tech 2010;23:53-6.

10. Saita K, Hoshino Y, Kikkawa I, Nakamura H. Posterior spinal shortening for paraplegia after vertebral collapse caused by osteoporosis. Spine (Phila Pa 1976) 2000;25:2832-5.

11. Suk SI, Kim JH, Lee SM, Chung ER, Lee JH. Anterior-posterior surgery versus posterior closing wedge osteotomy in posttraumatic kyphosis with neurologic compromised osteoporotic fracture. Spine (Phila Pa 1976) 2003;28:2170-5.

12. Imabayashi H, Matsukawa K, Yato Y, Saito M, Asazuma T, Nemoto K. Clinical examinabons of the posterior spinal surgery for osteoporotic vertebral fractures: mainly nonunion cases. J Spine Res 2010;1: 1864-7.
13. Nguyen HV, Akbarnia BA, van Dam BE, et al. Anterior exposure of the spine for removal of lumbar interbody devices and implants. Spine (Phila Pa 1976) 2006;31:2449-53.

14. Saville PD. A quantitative approach to simple radiographic diagnosis of osteoporosis: its application to the osteoporosis of rheumatoid arthritis. Arthritis Rheum 1967;10:416-22.

15. Fukuda F, Ueta T. Prediction of prognosis using modified Frankel classification in cervical spinal cord injured patients. Jpn J Rehabil Med 2001;38:29-33.

16. Bradford DS, McBride GG. Surgical management of thoracolumbar spine fractures with incomplete neurologic deficits. Clin Orthop Relat Res 1987;(218): 201-16.

17. Shikata J, Yamamuro T, Iida H, Shimizu K, Yoshikawa J. Surgical treatment for paraplegia resulting from vertebral fractures in senile osteoporosis. Spine (Phila Pa 1976) 1990;15:485-9.

18. Matsuyama Y, Goto M, Yoshihara H, et al. Vertebral reconstruction with biodegradable calcium phosphate cement in the treatment of osteoporotic vertebral compression fracture using instrumentation. J Spinal Disord Tech 2004;17:291-6.

19. Ataka H, Tanno T, Yamazaki M. Posterior instrumented fusion without neural decompression for incomplete neurological deficits following vertebral collapse in the osteoporotic thoracolumbar spine. Eur Spine J 2009;18:69-76.

20. Hoshino M, Matsuzaki H, Oda H. Posterior shortening surgery for kyphotic deformity after osteoporotic vertebral compression fracture. Rinsho Seikei Geka 2000;35:545-50.

21. Ichimura S, Hasegawa M, Satomi K, Asazuma T. Spinal shortening osteotomy for the paraplegia after osteoporotic vertebral fracture. Nippon Sekitsui Sekizuibyo Gakkai Zasshi 2008;19:652-5. 